liminary results based on a study of 450 cases, including controls, would appear to show that the clinical course of the above diseases is influenced beneficially, and the period in hospital significantly shortened, by treatment either with pure methionine in properily regulated dosage or by feeding patients with rapidly absorbable casein digests rich in methionine. In gravely ill patients, the results obtained by methionine treatment have been so striking as to leave no doubt as to the efficiency of the treatment, especially in those cases which have remained jaundiced for weeks or months and were in a state of icterus gravis when methionine treat. ment was initiated.

All our work has convinced us of the importance of an adequate protein intake, and more specifically of those proteins rich in methionine, in preventing and treating liver damage due to widely differing causes. We can therefore substantiate in large measure many of the suggestions put forward by Himsworth and Glynn as a result of their experimental work on rats.

J. BeATtiE.

J. MarshaLl.

Bernhard Baron Research Laboratories,

Royal College of Surgeons of England, London, W.C.2.

${ }^{1}$ Dixon, T. F., NATURE, 153, 289 (1944).

2 Best, C. H., and Lucas, C. C.. "Choline Chemistry and Signiflcance as a Dietary Factor", "Vitamins and Hormones", 1 (1943).

${ }^{8}$ Miller, L. L., and Whipple, G. H., J. Exp. Med., 76, 421 (1942).

4 Himsworth, H. P., and Glynn, L. E., Lancet, i, 457 (1944).

\section{Effect of Vitamin $C$ on the Adrenaline Content of the Adrenal Glands of Guinea Pigs}

I HAVE shown ${ }^{1}$ that the insulin content of the pancreas is markedly diminished in scurvy. This may be due to a lowered vitality of all the tissues of the scorbutic animals or to the existence of a specific relation between vitamin $\mathrm{C}$ and the insulin content of the pancreas. As is known, the adrenal glands are concerned in carbohydrate metabolism. The adrenaline content of the adrenal glands was, therefore, studied in scorbutic and normal guinea pigs.

Guinea pigs on a scorbutic diet for 22-25 days, and guinea pigs fed with normal diet for 15 days, were starved overnight and the adrenal glands were removed next morning. The adrenal glands were extracted with trichloracetic acid for adrenaline and ascorbic acid according to the method of Rees ${ }^{3}$. This method was adopted as the value of adrenaline thus determined in adrenal gland extracts was found to correspond to that determined biologically. The results are summarized in Table 1 and the statistical analyses of the individual figures are given in Table 2.
The results show a highly significant increase in the adrenaline content of the adrenal glands in scurvy as opposed to the decrease in the insulin content of the pancreas'. The diminished insulin content of the pancreas of the scorbutic guinea pigs is, therefore, not merely due to the lowered vitality of the tissues of the animals. The action of vitamin C on the secretion of insulin appears to be specific in some degree, as the insulin content of the pancreas is not altered in vitamin $\mathrm{B}_{1}$-deficiency ${ }^{4}$, which also affects carbohydrate metabolism.

\section{School of Tropical Medicine,}

SACHCHIDANANDA BANERJEE. (Mitra Research Scholar.) Calcutta. Feb. 16

1 Banerjee, S., Nature, 152, 329 (1943).

Barker, L. C., and Marrian, G. F., Biochem. J., 21, 1005 (1927). 8 Rees, H. G., Quart. J. Pharm. Pharmacol., 9, 659 (1936).

- Best, C. H., Haist, R. E., and Ridout, J. H., J. Physiol., 97, 137 (1939).

\section{White Plumage of Sea-Birds}

IN a recent communication ${ }^{1}$ on this subject, Craik makes some suggestions which we have attempted to examine further. A simple experiment in which conditions natural to fish were imitated was made on the flat roof of the Zoology Building here. The observer looked vertically upwards through a glass trough filled with water at a piece of opaque cardboard 3 in. $\times 5$ in. in size held $6 \mathrm{ft}$. above his head. The agitation of the water by the wind made visibility of details very poor. With any overcast sky, when the observer was presented successively with a black and a white piece of cardboard, he was unable to tell which was which. But when the sun was shining on them, the white cardboard was at once distinguished from the black.

Now it can be calculated that when the sky is overcast the brightness of a horizontal white surface illuminated by the light reflected from the sea is of the order of only a tenth of the brightness of the sky (the reflexion factor of water is 0.02 for normal incidence). Its contrast against the sky will thus be about 0.9 , as compared to 1.0 for a perfectly black object. At close range the horizontal parts of a white bird or aircraft must therefore be expected to appear (like the white cardboard) very dark against the sky. The difference of contrast just mentioned can, however, affect the critical range of visibility. The light scattered by the air-layer between the eye and an aeroplane will decrease the contrast between the latter and the sky. The intensity of scattered light needed to reduce the contrast from the value at close range to the smallest contrast perceptible by man (of the order of 0.01 ) is 0.89 for a white object and 0.99 for a black object. If the intensity

TABLE 1.

\begin{tabular}{|c|c|c|c|c|c|c|}
\hline $\begin{array}{l}\text { Scorbutic guinea pigs .. } \\
\text { Normal guinea pigs } . .\end{array}$ & $\begin{array}{c}\text { No. of animals } \\
\begin{array}{c}21 \\
20\end{array}\end{array}$ & $\begin{array}{l}\text { Average weight } \\
\text { per animal } \\
339 \mathrm{gm} . \\
315\end{array}$ & $\begin{array}{l}\text { Weight of adrenal } \\
\text { per } 100 \mathrm{gm} \text {. body wt. } \\
100 \cdot 0 \mathrm{mgm} \text {. } \\
61 \cdot 2\end{array}$ & $\begin{array}{c}\text { Ascorbic acid per } \\
\text { gm. of adrenal } \\
0.035 \text { mgm. } \\
1.002\end{array}$ & $\begin{array}{c}\text { Adrenaline per } \\
\text { gm. of adrenal } \\
719 \cdot 2 \mu \mathrm{gm} . \\
353 \cdot 8\end{array}$ & $\begin{array}{l}\text { Adrenaline per } \\
\text { pair of adrenals } \\
223 \mu \mathrm{gm} . \\
66\end{array}$ \\
\hline
\end{tabular}

TABLE 2.

Wt. of adrenal per Ascorbic acid per Adrenaline per $100 \mathrm{gm}$. of body wt. $\mathrm{gm}$. of adrenal $\mathrm{gm}$. of adrenal

Difference of the means

Standard

error of

$t$

$t$ Remarks $38.8 \mathrm{mgm}$.

$0.967 \mathrm{mgm}$. $365 \cdot 4 \mu \mathrm{gm}$

\section{$6 \cdot 187$
$6 \cdot 27$}

$6 \cdot 27$
Highly

significant
$0 \cdot 13078$

$7 \cdot 39$

significant of the scattered light is proportional to the distance, one would thus expect the range at which they became invisible to be about 10 per cent shorter for white than for black aircraft. We have assumed here that the critical factor affecting visibility is intensity discrimination, that is, the retinal image is large and the value of the differential threshold is not dependent on its size. But as the range 